\title{
Impact of vegetation die-off on spatial flow patterns over a tidal marsh
}

\author{
Stijn Temmerman, ${ }^{1}$ Pieter Moonen, ${ }^{2}$ Jonas Schoelynck, ${ }^{1}$ Gerard Govers, ${ }^{2}$ \\ and Tjeerd J. Bouma ${ }^{3}$
}

Received 3 December 2011; revised 13 January 2012; accepted 15 January 2012; published 14 February 2012.

[1] Large-scale die-off of tidal marsh vegetation, caused by global change, is expected to change flow patterns over tidal wetlands, and hence to affect valuable wetland functions such as reduction of shoreline erosion, attenuation of storm surges, and sedimentation in response to sea level rise. This study quantified for the first time the effects of large-scale (4 ha) artificial vegetation removal, as proxy of die-off, on the spatial flow patterns through a tidal marsh channel and over the surrounding marsh platform. After vegetation removal, the flow velocities measured on the platform increased by a factor of 2 to 4 , while the channel flow velocities decreased by almost a factor of 3 . This was associated with a change in flow directions on the platform, from perpendicular to the channel edges when vegetation was present, to a tendency of more parallel flow to the channel edges when vegetation was absent. Comparison with hydrodynamic model simulations explains that the vegetation-induced friction causes both flow reduction on the vegetated platform and flow acceleration towards the non-vegetated channels. Our findings imply that large-scale vegetation die-off would not only result in decreased platform sedimentation rates, but also in sediment infilling of the channels, which together would lead to further worsening of plant growth conditions and a potentially runaway feedback to permanent vegetation loss. Citation: Temmerman, S., P. Moonen, J. Schoelynck, G. Govers, and T. J. Bouma (2012), Impact of vegetation die-off on spatial flow patterns over a tidal marsh, Geophys. Res. Lett., 39, L03406, doi:10.1029/ 2011GL050502.

\section{Introduction}

[2] Vegetated tidal wetlands, such as salt marshes and mangroves, provide valuable ecosystem services to coastal societies [Barbier et al., 2008]. Wetland vegetation is known to reduce flood flow velocities [e.g., Leonard and Luther, 1995], which contributes to protection against shoreline erosion [e.g., Gedan et al., 2011] and to attenuation of landward storm surge propagation [e.g., Costanza et al., 2008; Wamsley et al., 2010]. Furthermore, the vegetation's effect on reduced flow velocities promotes sediment accretion through which tidal wetlands can sustain themselves

\footnotetext{
${ }^{1}$ Ecosystem Management Research Group, University of Antwerpen, Wilrijk, Belgium.

${ }^{2}$ Research Group for Physical and Regional Geography, Katholieke Universiteit Leuven, Heverlee, Belgium.

${ }^{3}$ Royal Netherlands Institute for Sea Research (NIOZ), Yerseke, Netherlands.

Copyright 2012 by the American Geophysical Union. 0094-8276/12/2011GL050502
}

with rising sea level [e.g., Allen, 1990; Kirwan and Temmerman, 2009; Morris et al., 2002]. Hence shoreline erosion, storm surge attenuation and sediment accretion are strongly affected by the hydrodynamic effects of the tidal wetland vegetation. However, large-scale vegetation die-off may occur with ongoing global change, such as recently observed in the Mississippi delta [Day et al., 2007], Southern U.S. salt marshes [Silliman et al., 2005], and Venice lagoon [Marani et al., 2007]. In order to predict the impacts of tidal wetland die-off, such as on reduced storm surge attenuation and reduced sediment accretion with sea level rise, it is crucial to understand the effects of large-scale vegetation die-off on the spatial flow patterns over a tidal wetland.

[3] To our knowledge, no previous field studies quantified the direct impact of tidal wetland die-off on large-scale spatial flow patterns. Existing field studies have traditionally focused on local flow conditions, either on the vegetated marsh platform [e.g., Leonard and Luther, 1995; Lightbody and Nepf, 2006], or within the channels that dissect the platform [e.g., French and Stoddart, 1992]. Relatively few studies have quantified the larger-scale spatial flow patterns, including the interaction between channel and platform flows [e.g., Christiansen et al., 2000; Davidson-Arnott et al., 2002; Temmerman et al., 2005a]. Such studies demonstrated that channel flow velocities are high (mostly $>0.5 \mathrm{~m} \mathrm{~s}^{-1}$ ), while the flow on the vegetated marsh platform is much slower (mostly $<0.1 \mathrm{~m} \mathrm{~s}^{-1}$ ) and is directed, during the flood phase, from the channel edges and seaward marsh edge towards the inner portions of the platform. Furthermore, it was demonstrated that only part of the over-marsh tidal prism (i.e. the total water volume that floods the marsh) is routed as concentrated flow through the channels, while up to $50 \%$ of the tidal prism may flow to and from the platform as sheet flow via the seaward marsh edge [Temmerman et al., 2005a]. However, to our knowledge, no previous field studies provided direct comparison of channel and platform flow patterns before and after removal of the tidal wetland vegetation.

[4] As a consequence, existing insights on the landscapescale hydrodynamic effects of tidal wetland vegetation primarily come from numerical modeling [e.g., D'Alpaos et al., 2007; Kirwan and Murray, 2007; Temmerman et al., 2007]. Hydrodynamic models showed that vegetationinduced friction on the platform causes, on the one hand, reduction of the local flow velocities on the vegetated platform, which is associated, on the other hand, with flow concentration and acceleration towards the non-vegetated channels due to their lower friction [e.g., Lawrence et al., 2004; Temmerman et al., 2005b]. As a consequence, simulation of die-off of the marsh platform vegetation does not 


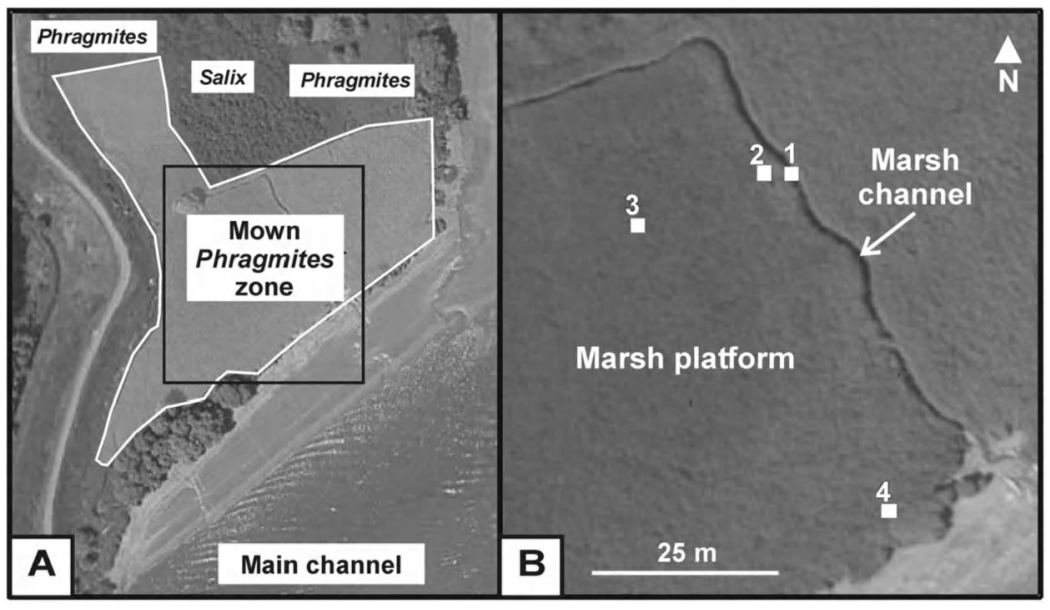

Figure 1. (a) Aerial picture overview of the studied tidal marsh. White-bordered polygon indicates location of the mown Phragmites zone; black-bordered rectangle indicates location of area shown in Figure 1b. (b) Detail showing location of the flow meters $(1-4)$.

only result in increased flow velocities and reduced sedimentation locally on the platform, but also in decreased flow velocities and sediment infilling in the channels [Temmerman et al., 2005b]. Similarly, adding vegetation patches to an originally bare tidal wetland model caused not only the reduction of flow velocities within the vegetation patches, but also flow acceleration and channel erosion in between the vegetation patches [Temmerman et al., 2007]. Hence these simulations suggest that die-back and reestablishment of vegetation have a major impact on spatial flow patterns over a tidal wetland, not only within the vegetation but also in the non-vegetated areas. This sequence of events, however, has yet to be documented using empirical field data. Here we present the results of a field experiment, in which the spatial patterns of channel and platform flow were measured on a tidal marsh (1) with presence of vegetation, and (2) after artificial removal of the vegetation canopy over a relatively large area $(\sim 4 \mathrm{ha})$, as a proxy for vegetation die-off.

\section{Methods}

[5] The experiment was done in a freshwater tidal marsh (Kijkverdriet) in the Scheldt estuary (Belgium) $\left(51.1214^{\circ} \mathrm{N}\right.$; $4.2642^{\circ} \mathrm{E}$ ). The tidal regime is semi-diurnal with a tidal range around $6 \mathrm{~m}$ during average spring tides and $4.5 \mathrm{~m}$ during average neap tides. The geomorphology of the marsh consists of a generally flat platform that is dissected by an intertidal channel (Figure 1) (mean \pm standard deviation of 519 total station measurements on the platform is $0.05 \pm$ $0.17 \mathrm{~m}$ relative to mean high water level). The platform is vegetated by a dense canopy of common reed (Phragmites australis (Cav.) Trin. ex Steud.). The channel bed is free of vegetation.

[6] Flow velocity measurements were carried out at one location in the central channel (location 1 in Figure 1b), where the channel was about $4 \mathrm{~m}$ wide and $1.4 \mathrm{~m}$ deeper than the average surrounding platform elevation. Measurements on the platform were done at three locations (locations 2 to 4 in Figure $1 \mathrm{~b}$ ). The combination of these 4 measuring locations allowed us to quantify the spatial flow patterns going through the channel (location 1), from the channel onto the platform (location 2) towards the inner marsh (location 3 ), and the flow directly entering the marsh via the marsh edge (location 4).

[7] The flow measurements were done during three campaigns with different vegetation conditions (Figure 2). The first campaign was in summer, when the Phragmites vegetation cover was maximal with a mean stem density of 190 stems $\mathrm{m}^{-2}(\mathrm{n}=10)$, mean stem diameter of $0.7 \mathrm{~cm}$ and stem height up to $3 \mathrm{~m}$. The second campaign was in autumn, when Phragmites had lost all of its leaves and only stems remained. For the third campaign in winter, the vegetation

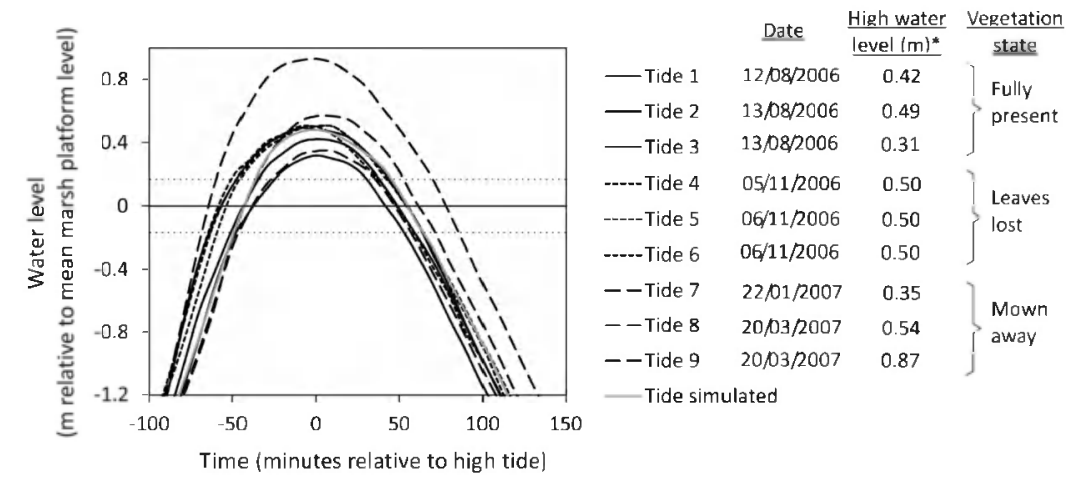

Figure 2. Overview of measured and simulated tides. 


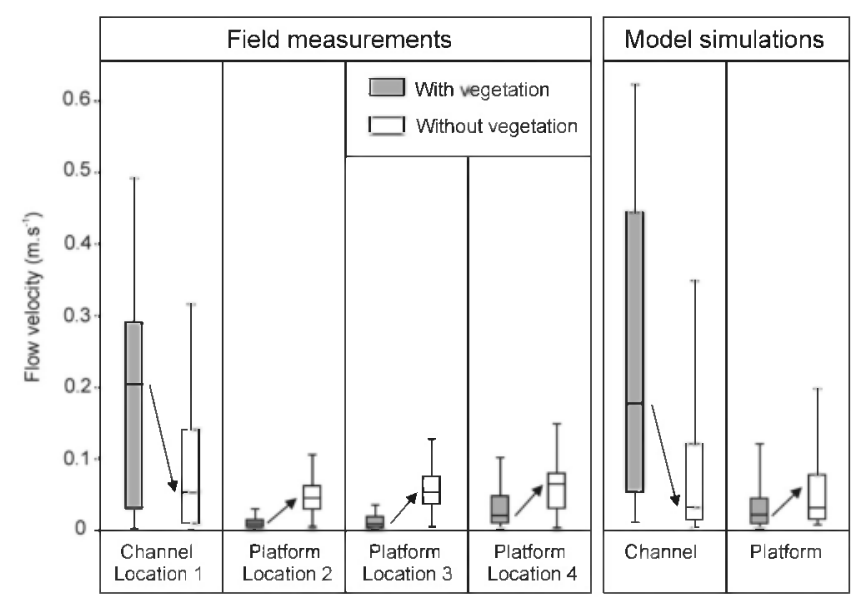

Figure 3. (left) Box plots of flow velocities measured in the channel (location 1) and on the platform (locations 2-4) during tides with vegetation (tides 1-3) and tides without vegetation on the platform (tides 7-9). (right) Box plots of simulated flow velocities in a marsh channel and platform (simulations in Figure 5).

cover was removed by mowing over an area of nearly 4 ha (Figure 1b). After mowing only short stems of max. $0.1 \mathrm{~m}$ high remained. For each of the three campaigns three high spring tides were measured with similar water depths on the marsh platform of on average $0.5 \mathrm{~m}$ at high tide (Figure 2). For the non-mown scenarios (tides 1-6) the vegetation canopy was not submerged, while for the mown scenarios (tides 7-9) the remaining reed stems $(<0.1 \mathrm{~m}$ high) were deeply submerged.

[8] The 4 measuring locations (Figure $1 b$ ) were equipped with electromagnetic flow meters (EMFs; Valeport), measuring with a frequency of $5 \mathrm{~Hz}$ in the horizontal $\mathrm{x}$ and $\mathrm{y}$ directions, resulting in time series of flow velocities and directions. The sensors of the EMFs were positioned at $0.08 \mathrm{~m}$ above the sediment bed. Time series of tidal water level change were recorded by a pressure sensor at location 1 in the channel with a frequency of $5 \mathrm{~Hz}$. Both the water level and flow velocity data were averaged over 1-minute time intervals prior to analyses. Positions and levels of all sensors were surveyed with a total station (Sokkia SET510k). The marsh platform and channel topography was mapped based on a combination of total station surveying and LIDAR data with a mean resolution of 1 point per $20 \mathrm{~m}^{2}$.

\section{Results}

[9] During tides 1-3 with presence of the full vegetation cover, the flow velocities were low on the vegetated platform (with peak velocities up to $0.2 \mathrm{~m} . \mathrm{s}^{-1}$ at locations 2-4), and were much higher in the bare channel (peak velocities up to $0.5 \mathrm{~m} . \mathrm{s}^{-1}$ at location 1) (Figure 3). After removal of the vegetation cover from the platform, the average flow velocities increased on the platform by a factor of 2 to 4 (with peak velocities up to $0.4 \mathrm{~m} . \mathrm{s}^{-1}$ ), while at the same time the average flow velocities decreased by almost a factor of 3 in the channel (peak velocities up to $0.3 \mathrm{~m} . \mathrm{s}^{-1}$ ) (Figure 3). These differences in flow velocities between the vegetated tides (tides 1-3) on the one hand, and nonvegetated tides (tides 7-9) on the other hand, were significant on all locations (Wilcoxon Rank Sum test, $\mathrm{p}<0.0001$ ). In most cases no significant differences were found in between the individual vegetated tides (except on location 2), and in between the individual non-vegetated tides (except for tide 7).

[10] Apart from the effect on flow velocities, the removal of the vegetation also affected the flow directions measured above the marsh platform. Since flow velocities on a tidal marsh platform typically peak at the beginning of flooding and end of drainage of the platform, average peak flow vectors for the first $15 \mathrm{~min}$ of the flood and last $15 \mathrm{~min}$ of the ebb were calculated and plotted on a map for all locations (Figure 4). The effect of vegetation removal on these peak flow directions is especially visible at location 2 near the channel edge, and to a lesser extent at location 4 near the marsh edge. With presence of the vegetation, the peak flood and ebb flow directions were at location 2 perpendicular to the channel edge (Figure 4). After removal of the vegetation, the platform flow direction near the channel edge (location 2) tended to become more parallel with the flow direction in the channel (location 1), i.e. the angle between platform and channel flood direction approached 45 degrees. A similar but less pronounced effect was observed at location 4 near the edge between the marsh and main estuarine channel. Here, with presence of the vegetation, the flood and ebb flow directions were also perpendicular to the marsh edge (Figure 4). After removal of the vegetation, the angle between the flow directions on the platform at location 4 and in the main estuarine channel became on average 75 degrees, meaning that the platform flow near the marsh edge became slightly more parallel to the main channel flow. The changes in platform flow directions between the vegetated tides (1-3) on the one hand, and non-vegetated tides (7-9) on the other



Figure 4. Map of average flow vectors measured in the marsh channel (location 1) and on the marsh platform (locations 2-4) for the flood phase (solid vectors; average of first 15 min of flood) and ebb phase (dashed vectors; average of last $15 \mathrm{~min}$ of ebb), for tides with vegetation (black vectors; tides 1-3) and tides without vegetation (grey vectors; tides 7-9). White area is the marsh platform. Black area is the marsh channel and part of bare tidal flat. The general flood direction in the main channel is indicated with white arrow (not to scale). 




Figure 5. Simulated depth-averaged flow velocity patterns at the beginning of flooding of a marsh platform dissected by a channel: (top) input bed level, (middle) simulated flow pattern with vegetation on the platform, and (bottom) flow pattern without vegetation [after Temmerman et al., 2005b].

hand, were significant at all locations (Wilcoxon Signed Rank test, $\mathrm{p}<0.0001$; the only exception is for flood tides at location 4).

\section{Discussion}

[11] To our knowledge, the present study provides, for the first time, empirical data on the direct effects of vegetation removal, as a proxy of vegetation die-off, on the spatial flow patterns over a tidal marsh, including the interactions between channel and platform flow. The removal of the platform vegetation resulted in a 2 to 4 -fold increase of the average flow velocities measured above the platform and an almost 3-fold reduction of the average flow velocities measured in the channel (Figure 3, left). These observations agree well with hydrodynamic model simulations (Figure 3, right) that were previously published [Temmerman et al., $2005 \mathrm{~b}$ ]. This good agreement between the field measurements and model simulations confirms that the measured changes in flow patterns are indeed attributed to the removal of the vegetation, and not so importantly to rather small differences in the measured tides (Figure 2). The comparison with hydrodynamic simulations explains that the vegetationinduced friction causes both flow reduction on the vegetated platform and flow acceleration towards the non-vegetated channels. Consequently, vegetation die-off results in both increased platform flow velocities and decreased channel velocities.

[12] The change in spatial flow velocity distributions was associated with a change in measured flow directions on the platform, from perpendicular to the channel edges when vegetation was present, to a tendency of more parallel flow to the channel edges when vegetation was absent (Figure 4). Very similar effects were also simulated with the hydrodynamic model [Temmerman et al., 2005b], showing that the vegetation-induced friction causes faster flood and ebb propagation through the channels, and consequently causes flooding and drainage of the platform with flow directions perpendicular to the channels (Figure 5, middle). Removal of this vegetation drag resulted in more equal flood and ebb propagation through the channels and over the platform, and hence in more parallel flow directions over the platform and in the channel (Figure 5, bottom).

[13] Our field experiments imply that vegetation die-off would result on the longer-term in runaway feedbacks between vegetation, flow and sediment dynamics, potentially leading to permanent tidal wetland loss. Our experiments indicate that vegetation die-off would result in (1) sediment infilling of the marsh channels, as the flow velocities in the channels drastically decrease, and (2) reduced sedimentation rates on the marsh platform, as the channel infilling would reduce sediment supply to the platform and the increased flow velocities on the platform would increase resuspension of sediments there, especially during the ebb phase. Such effects of vegetation removal on channel infilling and reduced platform accretion were also simulated by previous modeling [Temmerman et al., 2005b]. We emphasize that channel infilling would cause poorer soil drainage and thereby would have a feedback on further worsening of plant growth conditions. Many existing models that aim at simulating the long-term (decades to centuries) bio-morphodynamic response of tidal marshes to sea level rise [e.g., D'Alpaos et al., 2007; Kirwan et al., 2010; Kirwan and Murray, 2007; Marani et al., 2007] do not include such effect of vegetation die-off on channel infilling but only consider the effect on locally reduced platform accretion. Hence our experiments indicate that vegetation die-off might have more severe and irreversible effects on tidal wetland loss than previously thought.

[14] Finally our results may also have implications for the attenuating effect of tidal wetland vegetation on landward flood propagation during storm surges [e.g., Costanza et al., 2008; Wamsley et al., 2010]. Our results suggest that the wetland vegetation reduces the speed of flood propagation over the platform, but at the same time that the vegetation concentrates and accelerates flood flow velocities towards the channels. Hence this combined vegetation effect on overall storm surge attenuation is not so straightforward to predict, and should be incorporated in storm surge models that aim to simulate the protecting effect of wetlands.

[15] Acknowledgments. We gratefully acknowledge FWO for funding this project (grant $1503907 \mathrm{~N}$; NIOO-CEME for use of flow meters; the many people that assisted during the field work; especially nature managers Walter and Francois Vanhoyweghen and Tonny Temmerman for their fruitful collaboration.

[16] The Editor thanks two anonymous reviewers for their assistance in evaluating this paper.

\section{References}

Allen, J. R. L. (1990), Salt-marsh growth and stratification: A numerical model with special reference to the Severn Estuary, southwest Britain, Mar. Geol., 95, 77-96, doi:10.1016/0025-3227(90)90042-I.

Barbier, E. B., et al. (2008), Coastal ecosystem-based management with nonlinear ecological functions and values, Science, 319, 321-323, doi: $10.1126 /$ science. 1150349 .

Christiansen, T., P. L. Wiberg, and T. G. Milligan (2000), Flow and sediment transport on a tidal salt marsh surface, Estuarine Coastal Shelf Sci., 50, 315-331, doi:10.1006/ecss.2000.0548.

Costanza, R., O. Perez-Maqueo, M. L. Martinez, P. Sutton, S. J. Anderson, and K. Mulder (2008), The value of coastal wetlands for hurricane 
protection, Ambio, 37, 241-248, doi:10.1579/0044-7447(2008)37[241: TVOCWF $] 2.0 . \mathrm{CO} ; 2$.

D'Alpaos, A., S. Lanzoni, M. Marani, and A. Rinaldo (2007), Landscape evolution in tidal embayments: Modeling the interplay of erosion, sedimentation, and vegetation dynamics, $J$ Geophys. Res., 112, F01008, doi:10.1029/2006JF000537.

Davidson-Arnott, R. G. D., D. Van Proosdij, J. Ollerhead, and L. Schostak (2002), Hydrodynamics and sedimentation in salt marshes: Examples from a macrotidal marsh, Bay of Fundy, Geomorphology, 48, 209-231, doi:10.1016/S0169-555X(02)00182-4.

Day, J. W., et al. (2007), Restoration of the Mississippi delta: Lessons from hurricanes Katrina and Rita, Science, 315, 1679-1684, doi:10.1126/ science. 1137030

French, J. R., and D. R. Stoddart (1992), Hydrodynamics of salt marsh creek systems: Implications for marsh morphological development and material exchange, Earth Surf. Processes Landforms, 17, 235-252, doi:10.1002/esp.3290170304.

Gedan, K. B., M. L. Kirwan, E. Wolanski, E. B. Barbier, and B. R. Silliman (2011), The present and future role of coastal wetland vegetation in protecting shorelines: Answering recent challenges to the paradigm, Clim. Change, 106, 7-29, doi:10.1007/s10584-010-0003-7.

Kirwan, M. L., and A. B. Murray (2007), A coupled geomorphic and ecological model of tidal marsh evolution, Proc. Natl. Acad. Sci. U. S. A., 104, 6118-6122, doi:10.1073/pnas.0700958104.

Kirwan, M., and S. Temmerman (2009), Coastal marsh response to historical and future sea-level acceleration, Quat. Sci. Rev., 28, 1801-1808, doi:10.1016/j.quascirev.2009.02.022.

Kirwan, M. L., G. R. Guntenspergen, A. D'Alpaos, J. T. Morris, S. M Mudd, and S. Temmerman (2010), Limits on the adaptability of coastal marshes to rising sea level, Geophys. Res. Lett., 37, L23401, doi:10.1029/2010GL045489.

Lawrence, D. S. L., J. R. L. Allen, and G. M. Havelock (2004), Salt marsh morphodynamics: An investigation of tidal flows and marsh channel equilibrium, J. Coastal Res., 201, 301-316, doi:10.2112/1551-5036 (2004)20[301:SMMAIO]2.0.CO;2.

Leonard, L. A., and M. E. Luther (1995), Flow hydrodynamics in tidal marsh canopies, Limnol. Oceanogr., 40, 1474-1484, doi:10.4319/1o. 1995.40.8.1474
Lightbody, A. F., and H. M. Nepf (2006), Prediction of velocity profiles and longitudinal dispersion in emergent salt marsh vegetation, Limnol. Oceanogr., 51, 218-228, doi:10.4319/lo.2006.51.1.0218.

Marani, M., A. D'Alpaos, S. Lanzoni, L. Carniello, and A. Rinaldo (2007) Biologically-controlled multiple equilibria of tidal landforms and the fate of the Venice lagoon, Geophys. Res. Lett., 34, L11402, doi:10.1029/ 2007GL030178.

Morris, J. T., P. V. Sundareshwar, C. T. Nietch, B. Kjerfve, and D. R. Cahoon (2002), Responses of coastal wetlands to rising sea level, Ecology, 83, 2869-2877, doi:10.1890/0012-9658(2002)083[2869: ROCWTR]2.0.CO;2.

Silliman, B. R., J. Van de Koppel, M. D. Bertness, L. E. Stanton, and I. A. Mendelssohn (2005), Drought, snails, and large-scale die-off of southem U.S. salt marshes, Science, 310, 1803-1806, doi:10.1126/science. 1118229 .

Temmerman, S., T. J. Bouma, G. Govers, and D. Lauwaet (2005a), Flow paths of water and sediment in a tidal marsh: Relations with marsh developmental stage and tidal inundation height, Estuaries, 28, 338-352, doi:10.1007/BF02693917.

Temmerman, S., T. J. Bouma, G. Govers, Z. B. Wang, M. B. De Vries, and P. M. J. Herman (2005b), Impact of vegetation on flow routing and sedimentation patterns: Three-dimensional modeling for a tidal marsh, J. Geophys. Res., I10, F04019, doi:10.1029/2005JF000301.

Temmerman, S., T. J. Bouma, J. Van de Koppel, D. Van der Wal, M. B. De Vries, and P. M. J. Herman (2007), Vegetation causes channel erosion in a tidal landscape, Geology, 35, 631-634, doi:10.1130/G23502A.1.

Wamsley, T. V., M. A. Cialone, J. M. Smith, J. H. Atkinson, and J. D. Rosati (2010), The potential of wetlands in reducing storm surge, Ocean Eng., 37, 59-68, doi:10.1016/j.oceaneng.2009.07.018.

T. J. Bouma, Royal Netherlands Institute for Sea Research (NIOZ), PO Box 140, NL-4400 AC Yerseke, Netherlands.

G. Govers and P. Moonen, Research Group for Physical and Regional Geography, Katholieke Universiteit Leuven, Celestijnenlaan 200 E, B3001 Heverlee, Belgium.

J. Schoelynck and S. Temmerman, Ecosystem Management Research Group, University of Antwerpen, Universiteitsplein 1, B-2610 Wilrijk, Belgium. (stijn.temmerman(o)ua.ac.be) 